\title{
Exploring the Priced Factors in ICAPM in Japan
}

\author{
Chikashi Tsuji \\ Graduate School of Systems and Information Engineering, University of Tsukuba, Ibaraki, Japan \\ E-mail:mail_sec_low@minos.ocn.ne.jp \\ Received May 7, 2011; revised July 1, 2011; accepted July 10, 2011
}

\begin{abstract}
This paper investigates the priced factors in the Intertemporal Capital Asset Pricing Model (ICAPM) in the Tokyo Stock Exchange (TSE) in Japan. Focusing on the time-varying covariance risks derived by the multivariate Generalized Autoregressive Conditional Heteroskedasticity (GARCH) model, we find new priced state variables in Japan. That is, our empirical tests reveal that in the TSE, the time-varying covariance between market return and illiquidity measure and that between market return and the log change of the seasonally adjusted industrial production are statistically significantly priced state variables in the ICAPM.
\end{abstract}

Keywords: EGARCH-in-Mean Model, GARCH Model, GARCH-in-Mean Model, ICAPM, Multivariate GARCH Model

\section{Introduction}

Merton [1] developed the Intertemporal Capital Asset Pricing Model (ICAPM). ICAPM is a linear factor model with wealth and state variable that forecast changes in the distribution of future stock returns. Several studies such as [2], [3], [4], [5] and [6] tested this model in the US. However, in Japan, the pricing test of this ICAPM has little been conducted. Hence, our objective is to investigate the priced state variables in Merton's ICAPM in the Tokyo Stock Exchange (TSE).

This paper's novel characteristics are as follows. First, although we examine the ICAPM employing the similar approach of Lundblad [7], we focus on the covariance risks instead of volatility risk as in [7].

Second, we clarify new priced time-varying covariance risks that are related to illiquidity measure and industrial production. This is our most significant contribution in this paper.

The rest of the paper is organized as follows. Section 2 concretely describes Merton's ICAPM, Section 3 explains the data, Section 4 presents the empirical results, and Section 5 summarizes the paper.

\section{Theory and Research Design}

Lundblad [7] concretely documents Merton's ICAPM as follows:

$$
E_{t}\left[r_{M, t}-r_{f, t}\right]=\left[\frac{-J_{W W} W}{J_{W}}\right] \sigma_{M, t}^{2}+\left[\frac{-J_{W F}}{J_{W}}\right] \sigma_{M F, t},
$$

where $r_{M, t}$ is the market return, $r_{f, t}$ denotes the risk-free rate, $\sigma_{M, t}^{2}$ denotes the variance of market return, $\sigma_{M F, t}$ is the covariance between market return and other state variable. In addition, $\left[-J_{W W} W / J_{W}\right]$ denotes the investors' risk aversion, and $\left[-J_{W F} / J_{W}\right]$ is the coefficient that adjusts market risk premium in response to the changes of $\sigma_{M F, t}$. Further, $J(W(t), F(t), t)$ is the utility function which is related to investors' wealth, $W(t)$, and state variable, $F(t)$. (The subscripts of $W$ and/or $F$ mean partial differentiations by them.)

More concisely, for our empirical tests, we can write the ICAPM simpler as follows:

$$
r_{M, t}-r_{f, t}=\lambda_{M} \sigma_{M, t}^{2}+\lambda_{C} \sigma_{M F, t}+\varepsilon_{t} .
$$

To focus on the covariance risks, we first examine the following model (3):

$$
r_{M, t}-r_{f, t}=\lambda_{C} \sigma_{M F, t}+\varepsilon_{t},
$$

where the conditional variance of market return follows $\operatorname{GARCH}(1,1)$ model $([8])$ as the following model (4):

$$
\sigma_{M, t}^{2}=\delta_{0}+\delta_{1} \varepsilon_{t-1}^{2}+\delta_{2} \sigma_{M, t-1}^{2} .
$$

We next examine the ICAPM more rigorously by including the variance of market return as model (2), and where the conditional variance of market return follows Generalized Autoregressive Conditional Heteroskedasticity $(\mathrm{GARCH})(1,1)$ model $(4)$ or Exponential GARCH (EGARCH) $(1,1)$ model $([9])(5)$. That is, we estimate model (2) as GARCH-in-mean model or EGARCH-inmean model. 
$\ln \left(\sigma_{M, t}^{2}\right)=\delta_{0}+\delta_{1}\left(\left|\frac{\varepsilon_{t-1}}{\sigma_{M, t-1}}\right|\right)+\delta_{2}\left(\frac{\varepsilon_{t-1}}{\sigma_{M, t-1}}\right)+\delta_{3} \ln \left(\sigma_{M, t-1}^{2}\right)$

For calculating the time-varying covariance risks included in models (2) and (3), we use the multivariate GARCH model $([10,11])$.

\section{Data}

The full sample period of our data is from April 1985 to December 2009. We first compute the market risk premium: $r_{M, t}-r_{f, t}$. Where $r_{M, t}$ is the market return, which is calculated using Tokyo Stock Price Index (TOPIX) (from TSE), and $r_{f, t}$ is the rates of the one-month negotiable Certificate of Deposit (CD) (from Bank of Japan (BOJ)).

We also construct the following five covariance variables, CILLIQ, CDDY, CDEF, CDTERM, and CLCIP by using ILLIQ, DDY, DEF, DTERM, and LCIP, respectively. Where ILLIQ denotes the absolute value of return of the TSE First Section stocks (from TSE) divided by the total trading volume of the TSE First Section stocks (from TSE), DDY is the first difference of the dividend yield of the TSE First Section stocks (from TSE), DEF denotes the default spread between the yields of the long-term Nikkei Bond Index (from Nikkei, Inc.) and 10-year government bonds (from Quick Corp.), and DTERM means the first difference of the yield spread between the yields of 10-year government bonds (from Quick Corp.) and the one-month CD rates (from BOJ). Finally, LCIP is the log change of the seasonally adjusted industrial production (from Ministry of Economy, Trade and Industry). We then compute the above five variables, CILLIQ, CDDY, CDEF, CDTERM, and CLCIP, which are the covariances between market return $r_{M, t}$ and ILLIQ, DDY, DEF, DTERM, and LCIP, respectively. Again, these time-varying covariance risks are from the multivariate GARCH model.

\section{Empirical Results}

This section describes the characteristics of our data and empirical results for the ICAPM pricing in Japan. First, Table 1 exhibits the descriptive statistics of five variables, ILLIQ, DDY, DEF, DTERM, and LCIP. Table 1 shows that all variables are generally slightly positively skewed and possess excess kurtosis in comparison with the normal distribution. DDY and DTERM are the first differences of the raw variables because they have unit roots in the augmented Dickey-Fuller (ADF) tests. Table 2 displays the correlation coefficients among the above five variables. This table shows that the five variables are little correlated each other.

The empirical results of ICAPM pricing in Japan are exhibited in Tables 3 to 5 . Table 3 reports the results of our base tests by using model $(3)$ and the GARCH $(1,1)$ model (4). As described, market risk premium equation (3) includes the covariance variables derived by the multivariate GARCH model. Table 3 indicates that CILLIQ (time-varying covariance between market return and the illiquidity measure) and CLCIP (time-varying covariance between market return and the log change of the seasonally adjusted industrial production) are statistically significantly priced in ICAPM in the TSE.

Further, we implement two kinds of robustness checks. First, Table 4 exhibits the results of ICAPM pricing by using the GARCH-in-mean model. That is, we here incorporate both variance and covariance risks derived by the multivariate GARCH model into ICAPM as shown in (2), and where market return variance follows the GARCH $(1,1)$ model $(4)$. Table 4 again indicates that CILLIQ and CLCIP are statistically significantly priced in ICAPM in Japan.

Finally, we further perform the robustness checks by using the EGARCH-in-mean model. Namely, again we include both variance and covariance risks from the multivariate GARCH model in ICAPM (2), and where market return variance follows the EGARCH $(1,1)$ model (5). Table 5 again exhibits that CILLIQ and CLCIP are

Table 1. Descriptive statistics of state variables.

\begin{tabular}{cccccc}
\hline & \multicolumn{5}{c}{ Results of April 1985 to December 2009 } \\
\cline { 2 - 6 } & ILLIQ & DDY & DEF & DTERM & LCIP \\
\hline Mean & 0.295 & 0.004 & 0.218 & 0.002 & 0.047 \\
Median & 0.170 & 0.000 & 0.191 & -0.008 & 0.197 \\
Maximum & 2.193 & 0.420 & 1.497 & 1.128 & 4.485 \\
Minimum & 0.0004 & -0.380 & -0.572 & -1.349 & -8.969 \\
Std. Dev. & 0.328 & 0.068 & 0.262 & 0.294 & 1.739 \\
Skewness & 2.097 & 0.469 & 1.139 & 0.022 & -1.490 \\
Kurtosis & 9.042 & 10.805 & 7.409 & 6.288 & 290 \\
Observations & 297 & 296 & 297 & 296 & 297 \\
\hline
\end{tabular}


Table 2. Correlation coefficients of state variables.

\begin{tabular}{cccccc}
\hline & \multicolumn{5}{c}{ Results of April 1985 to December 2009 } \\
\cline { 2 - 5 } & ILLIQ & DDY & DEF & DTERM & LCIP \\
\hline ILLIQ & 1.000 & & & & \\
DDY & 0.080 & 1.000 & 1.000 & 1.000 & 1.000 \\
DEF & 0.217 & -0.008 & -0.086 & -0.013 & \\
DTERM & 0.032 & -0.137 & -0.118 & & \\
LCIP & -0.030 & -0.186 & & & \\
\hline
\end{tabular}

Table 3. ICAPM tests by GARCH model.

\begin{tabular}{|c|c|c|c|c|c|c|}
\hline & & \multicolumn{3}{|c|}{ Results of April 1985 to December 2009} & \multirow[b]{2}{*}{ Model 4} & \multirow[b]{2}{*}{ Model 5} \\
\hline & & Model 1 & Model 2 & Model 3 & & \\
\hline \multirow{2}{*}{ CILLIQ } & Coef. & $0.879 * *$ & & & & \\
\hline & $p$-value & 0.001 & & & & \\
\hline \multirow{2}{*}{ CDDY } & Coef. & & 0.258 & & & \\
\hline & $p$-value & & 0.862 & & & \\
\hline \multirow{2}{*}{$\mathrm{CDEF}$} & Coef. & & & 1.131 & & \\
\hline & $p$-value & & & 0.240 & & \\
\hline \multirow{2}{*}{ CDTERM } & Coef. & & & & -0.357 & \\
\hline & $p$-value & & & & 0.693 & \\
\hline \multirow{2}{*}{ CLCIP } & Coef. & & & & & $-0.547 * *$ \\
\hline & $p$-value & & & & & 0.032 \\
\hline LL & & -883.475 & -884.171 & -886.453 & -884.113 & -886.233 \\
\hline $\mathrm{SC}$ & & 6.045 & 6.070 & 6.065 & 6.070 & 6.064 \\
\hline
\end{tabular}

LL denotes log likelihood and SC is Schwarz criterion. ** denotes the statistical significance at the $5 \%$ level, and $*$ denotes the statistical significance at the $10 \%$ level.

Table 4. ICAPM tests by GARCH-in-mean model.

\begin{tabular}{|c|c|c|c|c|c|c|}
\hline \multicolumn{7}{|c|}{ Results of April 1985 to December 2009} \\
\hline & & Model 1 & Model 2 & Model 3 & Model 4 & Model 5 \\
\hline \multirow{2}{*}{ MV } & Coef. & 0.010 & 0.044 & 0.004 & 0.010 & 0.009 \\
\hline & $p$-value & 0.400 & 0.200 & 0.726 & 0.465 & 0.481 \\
\hline \multirow{2}{*}{ CILLIQ } & Coef. & $0.945^{* *}$ & & & & \\
\hline & $p$-value & 0.000 & & & & \\
\hline \multirow{2}{*}{ CDDY } & Coef. & & 5.698 & & & \\
\hline & $p$-value & & 0.185 & & & \\
\hline \multirow{2}{*}{$\mathrm{CDEF}$} & Coef. & & & 1.174 & & \\
\hline & $p$-value & & & 0.243 & & \\
\hline \multirow{2}{*}{ CDTERM } & Coef. & & & & -0.841 & \\
\hline & $p$-value & & & & 0.410 & \\
\hline \multirow{2}{*}{ CLCIP } & Coef. & & & & & $-0.478^{*}$ \\
\hline & $p$-value & & & & & 0.100 \\
\hline LL & & -883.098 & -883.232 & -886.384 & -883.861 & -885.713 \\
\hline $\mathrm{SC}$ & & 6.062 & 6.083 & 6.084 & 6.087 & 6.079 \\
\hline
\end{tabular}

LL denotes log likelihood and SC is Schwarz criterion. $* *$ denotes the statistical significance at the $5 \%$ level, and $*$ denotes the statistical significance at the $10 \%$ level. MV means market variance. 
Table 5. ICAPM tests by EGARCH-in-mean model.

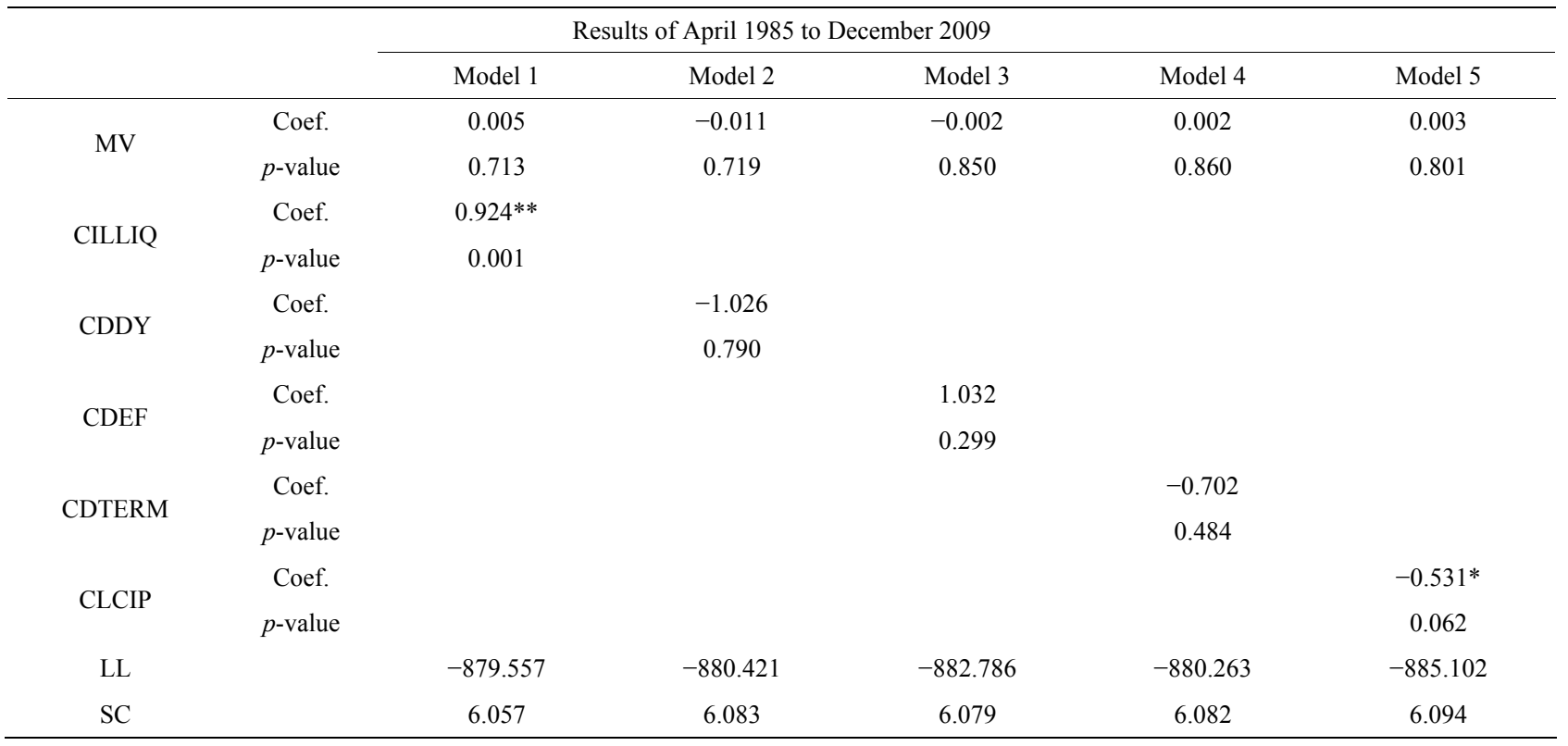

LL denotes log likelihood and SC is Schwarz criterion. **denotes the statistical significance at the $5 \%$ level, and * denotes the statistical significance at the $10 \%$ level. MV means market variance.

statistically significantly priced in ICAPM in the TSE. Therefore, we understand that these two time-varying covariance risks are stably priced in the TSE regardless of the model types.

To sum up, time-varying co-movements of market returns and market illiquidity are important dynamics for the market risk premium in the TSE. Further, we understand that time-varying covariance between market return and industrial production is also important as the determinant of the market risk premium in the TSE.

\section{Conclusions}

This paper explored the priced state variables in ICAPM in the TSE. Differently from the US previous study of [7], we focus on the time-varying covariance risks derived by the multivariate GARCH model. Our empirical examinations derived following interesting new findings.

First, for the TSE, we clarify that the time-varying covariance between market return and illiquidity measure is one of the strongly priced state variables in Merton's ICAPM.

Further, the time-varying covariance between market return and the log change of the seasonally adjusted industrial production is also the priced state variable in the ICAPM in Japan. These two variables' statistical significance is empirically robust regardless of the testing model types.

As above, new robust findings demonstrated in this paper will contribute to the body of academic researches of asset pricing in the field of financial economics. We consider that future related works using other data may be also valuable, and these works are our future tasks.

\section{Acknowledgements}

The author acknowledges the generous financial assistance of the Japan Society for the Promotion of Science and the Zengin Foundation for Studies on Economics and Finance. In addition, I thank the anonymous referee for the constructive comments to refine this paper. Furthermore, I greatly appreciate the invitation of the Editors to write to this journal.

\section{References}

[1] R. C. Merton, "An intertemporal Capital Asset Pricing Model," Econometrica, Vol. 41, No. 5, 1973, pp. 867-887.

[2] R. Petkova, "Do the Fama-French Factors Proxy for Innovations in Predictive Variables?" Journal of Finance, Vol. 61, No. 2, 2006, pp. 581-612. doi:org/10.1111/j.1540-6261.2006.00849.x

[3] M. A. Brennan, A. Wang and Y. Xia, "Estimation and test of a Simple Model of Intertemporal Capital Asset Pricing," Journal of Finance, Vol. 59, No. 4, 2004, pp. 1743-1775. doi:org/10.1111/j.1540-6261.2004.00678.x

[4] G. B. Turan, "The Intertemporal Relation between Expected Returns and Risk," Journal of Financial Economics, Vol. 87, No. 1, 2008, pp. 101-131. doi:org/10.1016/j.jfineco.2007.03.002

[5] M. P. Joshua and W. Mungo, "Average Correlation and 
Stock Market Returns," Journal of Financial Economics, Vol. 96, No. 3, 2010, pp. 364-380.

doi:org/10.1016/j.jfineco.2010.02.011

[6] Y. Jianfeng and Y. Yu, "Investor Sentiment and the Mean-Variance Relation," Journal of Financial Economics, Vol. 100, No. 2, 2011, pp. 367-381. doi:org/10.1016/j.jfineco.2010.10.011

[7] C. Lundblad, "The Risk Return Tradeoff in the Long Run: 1836-2003," Journal of Financial Economics, Vol. 85, No. 1, 2007, pp. 123-150.

doi:org/10.1016/i.jfineco.2006.06.003

[8] T. Bollerslev, "Generalized Autoregressive Conditional Heteroskedasticity," Journal of Econometrics, Vol. 31,
No. 3, 1986, pp. 307-327.

doi:org/10.1016/0304-4076(86)90063-1

[9] D. B. Nelson, "Conditional Heteroskedasticity in Asset Returns: A New Approach," Econometrica, Vol. 59, No. 2, 1991, pp. 347-370.

[10] R. F. Engle and K. F. Kroner, "Multivariate simultaneous generalized ARCH," Econometric Theory, Vol. 11, No. 1, 1995, pp. 122-150. doi:org/10.1017/S0266466600009063

[11] K. F. Kroner and V. K. Ng, "Modeling Asymmetric Comovement of Assets Returns," Review of Financial Studies, Vol. 11, No. 4, 1998, pp. 817-844. doi:org/10.1093/rfs/11.4.817 